\title{
Complex Day-to-day Movements of an Alpine Passerine May Act as an Insurance Against Environmental Variability
}

Arnaud Gian Barras ( $\sim$ arnaud.barras@iee.unibe.ch )

University of Bern

Felix Liechti

Swiss Ornithological Institute

Raphaël Arlettaz

University of Bern

\section{Research Article}

Keywords: accelerometer, elevational movements, barometer, conservation, high elevation, geolocator, migration, mountain bird

Posted Date: April 26th, 2021

DOI: https://doi.org/10.21203/rs.3.rs-184098/v2

License: (c) (i) This work is licensed under a Creative Commons Attribution 4.0 International License. Read Full License 


\section{Abstract}

Mountains naturally offer very contrasting habitat conditions, but their biodiversity is nowadays facing the extra challenge of adapting to rapid environmental shifts that are much more pronounced than in the lowlands. Among the possible adaptive responses of wildlife, intra- and inter-seasonal movements represent an important coping strategy that remains largely unexplored. We investigated the seasonal and day-to-day movements of the ring ouzel Turdus torquatus, a European mountain bird species that is declining in many parts of its distribution. We tracked individuals breeding in the Swiss Alps using geolocators, multi-sensor loggers and GPS. Of the birds traced to their non-breeding quarters, two thirds reached the Atlas Mountains while one third stayed in Spain, a region potentially more significant for overwintering than previously thought. The birds remained mostly above $1000 \mathrm{~m}$ throughout the annual cycle, highlighting a strict association of ring ouzels with mountain habitats. We also evidenced flexible daily elevational movements, especially upon spring arrival on the breeding grounds, which suggest adaptive potential in response to environmental variation. This study shows how modern technology can deliver deeper insights into animal movements, paving the way for refined assessments of species vulnerability to ongoing global change while providing basic conservation guidance.

\section{Introduction}

Information on year-round movement patterns is key for animal species conservation (Webster et al. 2002). In effect, migratory decisions can directly determine individual survival and reproductive success (Gill et al. 2001; Marra et al. 1998), impacting population dynamics (Norris and Marra 2007). The majority of animals inhabiting highly seasonal environments such as arctic and alpine ecosystems occupy their breeding habitat only during the short warm season. Consequently, the timing arrival at, and departure from these grounds needs to be finely tuned to the brief time window available for reproduction (Wingfield et al. 2004; Winkler et al. 2014). Given the particularly rapid pace of the environmental changes affecting these ecosystems (Flato and Boer 2001; Pepin et al. 2015), the capacity of birds to adjust and time their movement decisions in response to environmental shifts will be crucial for their long-term persistence (Dolman and Sutherland 1995; Winkler et al. 2014).

Movements of wildlife in mountain ecosystems have been little studied, even among well-investigated taxa such as mammals and birds of temperate biomes (Boyle and Martin 2015; Resano-Mayor et al. 2017). For instance, within-breeding season movements (Ceresa et al. 2020; Frey et al. 2016) or facultative latitudinal migration of bird species long considered as resident (Resano-Mayor et al. 2020) have been unveiled only recently, adding to our historical knowledge of seasonal elevational migration (Barçante et al. 2017; Hsiung et al. 2018; Tsai et al. 2021). In the same line, the importance of highelevation ecosystems as post-breeding or stopover grounds for migratory species may have been widely underestimated (Boyle and Martin 2015). The pronounced spatiotemporal heterogeneity that characterizes mountain ecosystems thus appears to foster regular movements throughout the annual cycle (Martin 2001), both latitudinally and elevationally. However, individual dispersal has remained poorly documented until the recent deployment of sophisticated tracking technology. 
The rapid development of tracking devices offers novel opportunities to study individual bird movements at unprecedented spatial and temporal scales and thus to tackle key conservation challenges (Katzner and Arlettaz 2020). For small birds, geolocators (GL) enable tracking individuals throughout the annual

cycle by means of simple measures of light intensity coupled with an internal clock. Still, this technology alone is not accurate enough to detect small-scale latitudinal movements (Fudickar et al. 2012), without mentioning elevational ones. This is possible with GPS tracking devices, which are now successfully deployed on small passerines (McKinnon and Love 2018), but the reduced lifespan of the embedded battery drastically limits the number of locations that can be collected. More recently, multi-sensor loggers (MSL) that combine GL with other sensors such as barometers and accelerometers have been developed (Liechti et al. 2018). Similarly to GL, MSL can collect data at high frequency and over long periods of time, additionally providing much deeper insights into individual spatial behaviour, including activity patterns, migratory schedules and flight altitude (Briedis et al. 2020; Dhanjal-Adams et al. 2018; Liechti et al. 2018). They thus represent a promising tool to better assess the three-dimensional movements of small animals such as passerines.

We investigated the annual movement patterns of a Western Palearctic passerine, the Alpine ring ouzel (Turdus torquatus alpestris), using these new tracking technologies. This subspecies of thrush breeds primarily in the mountain massifs of western and central Europe, from the Cantabrian to the Carpathian Mountains (Glutz von Blotzheim and Bauer 1988; Keller et al. 2020). It is believed to overwinter mainly in the Atlas Mountains in Morocco and Algeria (Glutz von Blotzheim and Bauer 1988) - in sympatry with individuals from the northern subspecies T. t. torquatus (Burfield 2002; Sim et al. 2015) - where the principal source of food is juniper (Juniperus sp.) berries (Ryall and Briggs 2006). Nonetheless, winter observations at the southern boundary of species breeding range (French western Alps and Pyrenees; Glutz von Blotzheim and Bauer 1988) suggest that central European populations are partially migratory or travel much shorter distances than their northern conspecifics, a classical pattern among European migrants (i.e. leapfrog migration; Newton 2008). Given the population declines observed in various parts of the species range, in particular at its periphery, it has been suggested that hunting and habitat deterioration in the principal migratory stopovers and/or on winter quarters may add to drivers negatively impacting the species on its breeding grounds (Burfield 2002; Sim et al. 2015). Yet, large-scale movements and thus migratory connectivity of the different ring ouzel populations are still poorly documented (Sim et al. 2015). Here, we used various tracking technologies to unravel the migration timing, routes and behaviour of ring ouzels breeding in the Central European Alps.

\section{Methods}

\section{Fieldwork and material}

Birds were captured and ringed at a single study site in Valais, Switzerland (46.33 N, 7.43 E; 1800-2100 $\mathrm{m}$ above sea level) during the breeding season, i.e. in April-June 2015-2020. Captures were performed with $2.5-\mathrm{m}$ high mistnets placed among potential foraging grounds or parallel to forest edges. Birds were 
sexed from plumage coloration and age - either second calendar year (2cy) or adult (>2cy) - determined based on the presence of a moult limit in the greater coverts (Jenni and Winkler 2020).

We used four types of loggers to record ring ouzel locations: simple geolocators (hereafter GL; model GDL2, Swiss Ornithological Institute (SOI), Switzerland); remote-download geolocators (hereafter also termed GL; model GDL-uTag, SOI, Switzerland); multi-sensor loggers (hereafter MSL; model GDL3-PAM, SOI, Switzerland) and GPS loggers (GPS; model nanoFix-GEO, PathTrack Ltd, UK). In addition to light intensity, the deployed MSL measured acceleration and atmospheric pressure at 5-min intervals (see Liechti et al. 2018 for details). GPS were programmed to record position once a week. All types of loggers were fixed on the birds using a leg-loop harness, made of elastic rubber or inelastic threaded nylon as concerns GL and MSL, and Teflon ribbon for GPS. The different types of loggers (see details in the Supplementary Table S1) weighed at most $2.6 \%$ of the mean ( \pm SD) body mass as measured from captured birds (males: $95.1 \pm 5.1 \mathrm{~g}, \mathrm{n}=191$; females: $100.8 \pm 8.9, \mathrm{n}=91$ ). The permit for bird capturing was delivered by the Swiss Federal Office for the Environment (F044-0799) and fitting of tracking devices was authorized by the Swiss Federal Food Safety and Veterinary Office, with all study protocols approved by the responsible ethics committee. Capturing and tagging were performed following all relevant guidelines and regulations of the abovementioned federal offices.

We equipped a total of 59 individuals with $62 \mathrm{GL}$ or MSL (three individuals were equipped twice) as well as 15 individuals with GPS between 2015-2019 (see Supplementary Table S1). Only seven out of the 62 $\mathrm{GL/MSL}$ were retrieved by recapture of the tagged bird, while data from another four GL could be downloaded remotely in the field. Two additional GL-tagged individuals had lost their logger at the time of recapture. We thus retrieved data from, in total, $5 \mathrm{MSL}$ and $6 \mathrm{GL}$. For MSL, data was complete (over one year) except for one device that had stopped recording as early as February in the year following tagging. Regarding GL, intense shading prevented data exploitation for two of them. Shading by feathers or the surrounding habitat may indeed strongly bias the measurements of sunrise or sunset times (hereafter twilights) and lead to spurious localizations. We additionally retrieved two out of the 15 GPS by recapture but both had malfunctioned, with locations available for only one GPS for just a month after deployment.

On subsequent years following ringing, we re-sighted 33.9\% (20/59) of the individuals equipped with GL and MSL, and $20 \%$ (3/15) of the GPS-tagged birds, to be compared with $29.9 \%(64 / 214)$ of the ring ouzels that had only been colour-ring marked at the study site and served as a control group. As assessed with Bayesian Cormack-Jolly-Seber models from visual re-sightings (following Kéry and Schaub 2012), apparent survival rates of GL- and MSL-tagged birds did not differ from the control group $(\beta=0.27,95 \%$ $\mathrm{Cl}:-0.92$ to 1.66$)$, while we evidenced a detrimental effect of the slightly heavier GPS loggers $(\beta=-1.74$, $95 \% \mathrm{Cl}:-3.32$ to -0.42$)$.

\section{Analyses}

All analyses were performed with the software R version 3.6.2 (R Development Core Team 2019) using the packages TwGeos (Wotherspoon et al. 2016), GeoLight (Lisovski and Hahn 2012), SGAT (Sumner et 
al. 2009) and PAMLr (Dhanjal-Adams 2019), following the general framework described in Lisovski et al. (2020). Starting with data from the five MSL, we classified bird behaviour into four categories of activity (no activity, low activity, high activity and migration) based on acceleration measures, using the algorithm from the classifyFLAP function in PAMLr. We defined migratory flights as those equal or longer than 30 min, which corresponds to at least six consecutive readings with ascertained flight activity. Based on this data, we defined the migratory schedule and separated the annual cycle into four periods: post-breeding, autumn migration, non-breeding (i.e. overwintering) and spring migration (the locations during reproduction being irrelevant here). The post-breeding period started on the day of the first nocturnal flight in June or July and lasted up to the autumn migration departure, which was defined as the first true migratory flight after August $1^{\text {st }}$. We assumed that birds had reached their non-breeding residence area as soon as they had stayed for at least two weeks in a row at the same place after October $1^{\text {st }}$. Spring migration started with the first ascertained migratory flight in March.

In a second step, we converted readings of atmospheric pressure into $\mathrm{m}$ above sea level (hereafter $\mathrm{m}$ asl) using the function altitudeCALC in the PAMLr package, which is based on the hypsometric equation that assumes standard atmospheric conditions (Liechti et al. 2018; Stull 2016). Hence, estimates of elevation are rather precise, but can be biased by natural variations in atmospheric pressure, i.e. influenced by the so-called «high- and low-pressure areas». Such shifts in pressure are, however, fairly slow and minor (maximum of $2 \mathrm{hPa} \mathrm{h}^{-1}$ ) so that they would not generate abrupt changes in estimated elevation (Liechti et al. 2018). Furthermore, daily fluctuations in atmospheric pressure, called atmospheric tides, reach at most $3 \mathrm{hPa}$ in the tropics (Le Blancq 2011), potentially inducing a maximal daily altitudinal deviation of only ca $30 \mathrm{~m}$ for a given location. We summarized the elevation information as the median and range (minimum to maximum) for each of the four periods of the annual cycle, treating readings during migratory bouts separately.

Finally, we derived geographic positions of the nine birds for which light-intensity data was available and of sufficient quality. We first defined twilights using TwGeos and then categorized those into residency and movement periods. For MSL, this distinction was based on the migratory flights that were identified as described previously. We considered only periods of eight consecutive days without migratory flight as true stopovers, given the noise in the data and thus the need of longer periods to estimate accurate locations. For GL, the distinction was done using the function changeLight in GeoLight, again setting a threshold of eight days for distinguishing a stopover. We used «in-habitat» calibration of the sun elevation angles (zero and median) for parameterizing the error distribution around the twilight times (Lisovski and Hahn 2012), i.e. using as a reference the period during which a bird was for sure present at its breeding site. We then modeled the migration trajectory as well as stopover and residency locations using SGAT. We chose a grouped Estelle model, where estimates within residency periods are grouped together to increase spatial precision (Lisovski et al. 2020). We forced residency periods to occur on land only, whereas movement was not constrained spatially but flight speed assumed to follow a gamma distribution $(\beta=2.2, S D=0.08)$. The starting point of each trajectory track was fixed at the very breeding location, as was the end point, except for the individual whose logger stopped recording in the middle of 
winter. To fit the Estelle model, we first drew 1'000 initial samples using a 'modifiedGamma' model (i.e. relaxed model, allowing negative errors on twilight times), tuned it 5 times with 300 iterations using a 'Gamma' distribution. We shall here report median estimates $\pm 95 \%$ credible intervals (Cl; based on 2.5 and $97.5 \%$ quantiles) from a final run with 2 '000 iterations to ensure convergence.

\section{Results}

\section{Migratory schedule}

We obtained a complete annual migratory schedule for four individuals, and partial for a fifth (Table 1). Most of the migratory movements (i.e. flights $\geq 30 \mathrm{~min}$ ) took place at night (mean $=96.7 \%$, range: $92.7-$ 98.8\%). Post-breeding dispersal started between the second half of June and the first 10 days of July (Table 1), although it consisted of only one single short nocturnal flight (<30min) for bird AdM-3 (Fig. 1). Actual departures into fall migration were observed 45-103 days after the onset of post-breeding dispersal, differing markedly between all five individuals (Table 1). Most of the autumn migratory flights occurred in October for all birds (Fig. 1; Supplementary Fig. S1). Inter-individual differences in the onset of fall migration resulted in a large variation in the duration and speed of migration (Table 1), but the cumulative sum of flight hours varied little in all three adult males, with 44,43 and $45 \mathrm{~h}$, respectively (AdM-1, -2, -3; Table 1, Supplementary Fig. S1). The flight duration of the sole adult female (AdF) with a full tracking record was much briefer $(31 \mathrm{~h})$, owing to the shorter distance to her non-breeding site (Table 1). A fourth younger male (second calendar year; $2 c y M$ ) revealed high migratory activity in August and September already, resulting in a total of $75 \mathrm{~h}$ in migratory flights. The number of days necessary to reach the final non-breeding destination varied between 27 and 55 days (except for $2 c y M$ that was hyperactive in the late summer, see above), although migratory flights occurred only during 7-13 nights (31 nights for 2cyM). Nocturnal migratory flights were also obvious for two individuals (2cyM and AdM-1) in December and January (Fig. 1), evidencing potentially significant movements in the middle of the winter (Supplementary Fig. S2). Spring migration from the four birds that yielded data took place in a fairly narrow temporal window of 9-20 days (Table 1, Fig. 1), being thus much shorter than fall migration, and also briefer in cumulative flight hours and number of migratory nights (Table 1).

\section{Migration routes}

An insufficient quality of data combined with migratory activity typically taking place around the equinoxes dramatically limited our ability to precisely reconstruct the migratory trajectories and locate the stopovers for most of our birds. Nevertheless, the GPS information available from a single bird revealed a $140-\mathrm{km}$ eastwards movement at the end of June and early July (over 20 days), hence initiating postbreeding dispersal, in line with the findings obtained with MSL. However, nocturnal flight durations of MSL-tagged birds at that time of the year (0.25-4.7 $\mathrm{h}$ in total) suggest that only one other bird could have covered a similarly long distance during the post-breeding period (AdM-2; Fig. 1). Concerning nonbreeding grounds, GL and MSL data revealed that six birds spent the winter in North Africa, while three others most likely overwintered in the Iberian Peninsula (Fig. 2). Among the six birds wintering in 
Maghreb, two were localized in the Middle Atlas, two in the High Atlas and one in the Anti-Atlas, all five in Morocco. The location estimates of a sixth bird (2cyM) further south in Algeria are inconsistent with elevation readings (Fig. 3) and probably biased southwards (see also Supplementary Fig. S2); this individual may actually have overwintered in the Anti-Atlas or High Atlas massif. Among the three ring ouzels staying in Spain, one individual overwintered in the meridional Sistema Ibérico, (AdM-4), another in the Sistema Prebético (AdF), while the winter quarters of the third bird (AdM-5) are unclear (average locations in the Mediterranean) and could be situated in the eastern part of the Sistema Prebético (Fig. 2).

\section{Elevational movements}

The median elevation during the post-breeding period was, for all five birds tagged with MSL, above the average elevation of the core study area (i.e. >1950 m asl; Fig. 3), indicating movements to sites mostly above the timberline after reproduction. The median elevation of stopovers during the autumn migration (in contrast to their location, the elevation of stopovers was easily retrieved from barometer data) was generally above $1860 \mathrm{~m}$ asl (Fig. 3), but three birds stopped below $1000 \mathrm{~m}$ asl for a single day. The maximal estimated flight elevation was reached during the fall nocturnal migration by bird AdF on October $10^{\text {th }}$, with $4270 \mathrm{~m}$ asl. The median elevation of non-breeding grounds was always greater than $1500 \mathrm{~m}$ asl for every individual, irrespective of their location. Spring stopover sites were on average at a lower elevation than autumn stopovers (Fig. 3). Finally, year-round measurements revealed periods with marked elevation differences between day and night within a 24-h cycle (Supplementary Fig. S3). Birds were then clearly commuting every day to areas located either below (pre-breeding) or above (postbreeding) the elevation of their location overnight. This phenomenon, confirmed via direct field observations, was particularly marked during the two to three weeks following spring arrivals, when birds flew to foraging grounds situated several hundred meters below the breeding area (Fig. 4). A similar behaviour was also detected later in the season, following late snowfalls (Fig. 4).

\section{Discussion}

Using electronic tracking technology, we documented the seasonal movements of Alpine ring ouzels breeding in the Swiss Alps. From a technical viewpoint, if modern tracking methods offer new opportunities for in-depth ecological research, we must not forget that geolocation is particularly challenging when deployed in mountainous environments. This is because the complex topography influences the measurement of day length, yielding less accurate location estimates. Multi-sensor loggers may constitute a valuable alternative as they enable measuring elevation and behaviour at an unprecedented fine temporal resolution. Here, it is the combination of different methods that provided us with a clear picture of the year-round locations and migratory behaviour of the ring ouzel. We found that the species is tightly associated with mountain ranges and high elevations at all stages of its life cycle, including during migratory stopovers. This highlights that temperate mountain ecosystems are important not only for the reproduction of Western Palearctic avifauna but also for its dispersal and migration, in line with what has been documented in the Nearctic (Boyle and Martin 2015; Martin 2001). For the ring ouzel, mountain massifs actually constitute a network of stepping stones in the western European 
landscape that is otherwise dominated by unsuitable lowland habitat. The behavioural pattern illustrated here may be partly shared by at a least another typical inhabitant of European alpine ecosystems, the white-winged snowfinch Montifringilla nivalis (see Resano-Mayor et al. 2020). Given the faster climate shifts at high elevations (Pepin et al. 2015) and shrinking habitat due to the pyramid shape of mountains, these mountain species are regarded as especially vulnerable to rapid climate change (La Sorte and Jetz 2010). The strict reliance on mountains for various parts of the annual cycle might render them even more sensitive, compared to other alpine species which also use lowland habitats (e.g. northern wheatear Oenanthe oenanthe or water pipit Anthus spinoletta).

Our results confirm the important role played by the Atlas Mountains for wintering ring ouzels (Glutz von Blotzheim and Bauer 1988; Ryall and Briggs 2006; Sim et al. 2015): two thirds of our birds spent the cold season in Maghreb. The remaining third overwintered in the Iberian Peninsula, suggesting that Spanish mountain ranges may represent another, so far unrecognized key wintering hotspot, at least for the Alpine population. Observations of ring ouzels in winter in the Atlas and Spanish massifs have shown that they feed mainly on juniper berries (of Juniperus thurifera, communis, oxycedrus, phoenica and cedrus), playing a key role in seed dispersal (Herrera 1985; Rumeu et al. 2009; Ryall and Briggs 2006; Zamora 1990). Overwintering in Spain certainly entails shorter, i.e. energetically less demanding flights for Alpine ring ouzels. Nonetheless, the reason for choosing Spain may lie elsewhere. In effect, the fructification of junipers is highly cyclic in the Spanish highlands (Tellería et al. 2014; Tellería et al. 2011), as it probably also is in North Africa (Ryall and Briggs 2006). Since thrushes are known to actively track food sources (Tellería et al. 2014; Tellería et al. 2011), the local availability of juniper berries probably explains the whereabouts of ring ouzels in winter. Hence, the few sudden movements we could document in winter may correspond to relocations to regions providing good food supplies. An ability to move between feeding areas could make ring ouzels somehow resilient to the progressive loss of their foraging habitat in the Maghreb, notably in Morocco where juniper forests are systematically overexploited for firewood (Ryall and Briggs 2006).

Finally, we also evidenced complex patterns of elevational movements. First, birds retreated to lower elevations following late snowfalls in spring. These movements triggered by adverse weather conditions at the breeding site have been described for numerous bird species in several mountain ranges (Boyle et al. 2010; Hahn et al. 2004; O'Neill and Parker 1978). More surprisingly, ring ouzels also performed daily elevational movements that have to our knowledge never been documented in such detail at the individual level apart from aerial insectivores (see Dreelin et al. 2018). The most patent demonstration of this phenomenon was upon arrival of ring ouzels on their Alpine breeding grounds in April, when those are still covered by a dense snowpack. Birds typically overnight in their future breeding territories, males vocally signaling their occupancy at dawn and dusk (Glutz von Blotzheim and Bauer 1988). The rest of the day, they apparently visited snow-free meadows at lower elevations to forage, usually in the montane and subalpine belts, depending on seasonal, year-specific snow conditions (Fig. 4). Later in the season, with the advancement of the snowmelt which frees the first patches of alpine grasslands within the breeding area, they stopped commuting. Daily elevational migration may enable birds to settle in highelevation breeding grounds very early in the year, sometimes when those are still inhospitable, and thus 
some sort of insurance against missing the brief time window suitable for breeding (Barras et al. 2020; Barras et al. 2021). Indeed, ring ouzels migrate much faster in the spring than in the autumn, a pattern commonly observed across various migration flyways and species (Nilsson et al. 2013; Schmaljohann 2018). However, this contrasts with the migration strategy of other mountain or arctic bird species, that make prolonged pre-breeding stopovers at lower elevations or latitudes not far from their reproductive grounds, waiting there for the snowmelt at their nearby breeding sites and/or building fat reserves (de Zwaan et al. 2019; Kölzsch et al. 2016). With their daily elevational movements, ring ouzels have thus found an innovative solution to cope with the highly seasonal and unpredictable breeding environment that prevails at high elevation. The question remains whether this high spatial flexibility will also procure ring ouzel - and other cold-adapted bird species (Hahn et al. 2004; Resano-Mayor et al. 2020; Wingfield et al. 2004) - some buffer against the dramatic impacts of climate and land-use change that are going to accentuate into the future.

\section{Declarations}

Acknowledgements: We are indebted to all people who helped with fieldwork, in particular J. ResanoMayor, I. Candolfi and Y. Rime. We are also grateful to E. Baechler and N. Znakovaité for technical support, as well as K. Dhanjal-Adams for the assistance in data processing. We thank MeteoSwiss for providing weather data.

Funding: FL was supported by the Swiss Federal Office for the Environment for geolocator development (UTF-Nr. 254, 332, 363, 400).

Author contributions: All authors contributed to the study conception and design. Data collection and analysis was performed by $A B$. $A B$ lead writing of the manuscript and all authors read, thoroughly edited and approved the final manuscript.

Conflicts of interest. The authors declare that they have no conflict of interest

Permit. Permission for bird capturing was delivered by the Swiss Federal Office for the Environment (F044-0799) and authorization for fitting birds with tracking devices by the Swiss Federal Food Safety and Veterinary Office.

Data accessibility statement. Data that support the findings of this study will be made available from the figshare repository upon publication.

\section{References}

Barçante L, Vale MM, Alves MAS (2017) Altitudinal migration by birds: A review of the literature and a comprehensive list of species. Journal of Field Ornithology 88:321-335

doi:https://doi.org/10.1111/jofo.12234 
Barras AG, Marti S, Ettlin S, Vignali S, Resano-Mayor J, Braunisch V, Arlettaz R (2020) The importance of seasonal environmental factors in the foraging habitat selection of Alpine Ring Ouzels Turdus torquatus alpestris. Ibis 162:505-519 doi:https://doi.org/10.1111/ibi.12764

Barras AG, Niffenegger CA, Candolfi I, Hunziker YA, Arlettaz R (2021) Nestling diet and parental food provisioning in a declining mountain passerine reveal high sensitivity to climate change. Journal of Avian Biology 52:e02649 doi:https://doi.org/10.1111/jav.02649

Boyle WA, Martin K (2015) The conservation value of high elevation habitats to North American migrant birds. Biological Conservation 192:461-476 doi:https://doi.org/10.1016/j.biocon.2015.10.008

Boyle WA, Norris DR, Guglielmo CG (2010) Storms drive altitudinal migration in a tropical bird. Proceedings of the Royal Society B: Biological Sciences 277:2511-2519

doi:https://doi.org/10.1098/rspb.2010.0344

Briedis M, Beran V, Adamík P, Hahn S (2020) Integrating light-level geolocation with activity tracking reveals unexpected nocturnal migration patterns of the tawny pipit. Journal of Avian Biology 51:e02546 doi:https://doi.org/10.1111/jav.02546

Burfield IJ (2002) The breeding ecology and conservation of the ring ouzel Turdus torquatus in Britain. University of Cambridge

Ceresa F, Brambilla M, Monrós JS, Rizzolli F, Kranebitter P (2020) Within-season movements of Alpine songbird distributions are driven by fine-scale environmental characteristics. Scientific Reports 10:5747 doi:https://doi.org/10.1038/s41598-020-62661-0

de Zwaan DR, Wilson S, Gow EA, Martin K (2019) Sex-specific spatiotemporal variation and carry-over effects in a migratory alpine songbird. Frontiers in Ecology and Evolution 7:285 doi:https://doi.org/10.3389/fevo.2019.00285

Dhanjal-Adams K (2019) PAMLr: Suite of functions for manipulating pressure, activity, magnetism and light data in R. R package ver. 0.1.0.

Dhanjal-Adams KL, Bauer S, Emmenegger T, Hahn S, Lisovski S, Liechti F (2018) Spatiotemporal group dynamics in a long-distance migratory bird. Current Biology 28:2824-2830 doi:https://doi.org/10.1016/j.cub.2018.06.054

Dolman PM, Sutherland WJ (1995) The response of bird populations to habitat loss. Ibis 137:38-46 doi:https://doi.org/10.1111/j.1474-919X.1995.tb08456.x

Dreelin RA, Shipley JR, Winkler DW (2018) Flight behavior of individual aerial insectivores revealed by novel altitudinal dataloggers. Frontiers in Ecology and Evolution 6 doi:10.3389/fevo.2018.00182 
Flato GM, Boer GJ (2001) Warming asymmetry in climate change simulations. Geophysical Research Letters 28:195-198 doi:https://doi.org/10.1029/2000GL012121

Frey SJK, Hadley AS, Betts MG (2016) Microclimate predicts within-season distribution dynamics of montane forest birds. Diversity and Distributions 22:944-959 doi:https://doi.org/10.1111/ddi.12456

Fudickar AM, Wikelski M, Partecke J (2012) Tracking migratory songbirds: Accuracy of light-level loggers (geolocators) in forest habitats. Methods in Ecology and Evolution 3:47-52 doi:https://doi.org/10.1111/j.2041-210X.2011.00136.x

Gill JA, Norris K, Potts PM, Gunnarsson TG, Atkinson PW, Sutherland WJ (2001) The buffer effect and large-scale population regulation in migratory birds. Nature 412:436-438

doi:https://doi.org/10.1038/35086568

Glutz von Blotzheim UN, Bauer KM (1988) Turdus torquatus Linnaeus 1758 - Ringdrossel, Ringamsel. Band 11/II. In: Glutz von Blotzheim UN (ed) Handbuch der Vögel Mitteleuropas, vol 11/II. AULA-Verlag, Wiesbaden, pp 801-838

Hahn TP, Sockman KW, Breuner CW, Morton ML (2004) Facultative altitudinal movements by mountain white-crowned sparrows (Zonotrichia leucophrys oriantha) in the Sierra Nevada. The Auk 121:1269-1281 doi:https://doi.org/10.1093/auk/121.4.1269

Herrera CM (1985) Habitat-consumer interactions in frugivorous birds. In: Cody ML (ed) Habitat selection in birds. Academic Press, London,

Hsiung AC, Boyle WA, Cooper RJ, Chandler RB (2018) Altitudinal migration: Ecological drivers, knowledge gaps, and conservation implications. Biological Reviews 93:2049-2070

doi:https://doi.org/10.1111/brv.12435

Jenni L, Winkler R (2020) Moult and ageing of European passerines. Bloomsbury Publishing Plc, London

Katzner TE, Arlettaz R (2020) Evaluating contributions of recent tracking-based animal movement ecology to conservation management. Frontiers in Ecology and Evolution 7:519 doi:https://doi.org/10.3389/fevo.2019.00519

Keller V et al. (2020) European Breeding Bird Atlas 2: Distribution, abundance and change. European Bird Census Council \& Lynx Edicions, Barcelona

Kéry M, Schaub M (2012) Bayesian population analysis using WinBUGS: a hierarchical perspective. Academic Press, Waltham

Kölzsch A, Müskens GJDM, Kruckenberg H, Glazov P, Weinzierl R, Nolet BA, Wikelski M (2016) Towards a new understanding of migration timing: Slower spring than autumn migration in geese reflects different 
decision rules for stopover use and departure. Oikos 125:1496-1507

doi:https://doi.org/10.1111/oik.03121

La Sorte FA, Jetz W (2010) Projected range contractions of montane biodiversity under global warming. Proceedings of the Royal Society B: Biological sciences 277:3401-3410 doi:https://doi.org/10.1098/rspb.2010.0612

Le Blancq F (2011) Diurnal pressure variation: The atmospheric tide. Weather 66:306-307 doi:https://doi.org/10.1002/wea.857

Liechti F, Bauer S, Dhanjal-Adams KL, Emmenegger T, Zehtindjiev P, Hahn S (2018) Miniaturized multisensor loggers provide new insight into year-round flight behaviour of small trans-Sahara avian migrants. Movement Ecology 6:19 doi:https://doi.org/10.1186/s40462-018-0137-1

Lisovski S et al. (2020) Light-level geolocator analyses: A user's guide. Journal of Animal Ecology 89:221236 doi:https://doi.org/10.1111/1365-2656.13036

Lisovski S, Hahn S (2012) GeoLight - processing and analysing light-based geolocator data in R. Methods in Ecology and Evolution 3:1055-1059 doi:https://doi.org/10.1111/j.2041-210X.2012.00248.x

Marra PP, Hobson KA, Holmes RT (1998) Linking winter and summer events in a migratory bird by using stable-carbon isotopes. Science 282:1884-1886 doi:https://doi.org/10.1126/science.282.5395.1884

Martin K (2001) Wildlife in alpine and sub-alpine habitats. In: Johnson DH, O’Neil TA (eds) WildlifeHabitat Relationships in Oregon and Washington. Oregon State University Press,

McKinnon EA, Love OP (2018) Ten years tracking the migrations of small landbirds: Lessons learned in the golden age of bio-logging. The Auk 135:834-856, 823 doi:https://doi.org/10.1642/AUK-17-202.1

Newton I (2008) The migration ecology of birds. Academic Press, Elsevier, London

Nilsson C, Klaassen RHG, Alerstam T (2013) Differences in speed and duration of bird migration between spring and autumn. The American Naturalist 181:837-845 doi:https://doi.org/10.1086/670335

Norris RD, Marra PP (2007) Seasonal interactions, habitat quality, and population dynamics in migratory birds. The Condor 109:535-547 doi:https://doi.org/10.1093/condor/109.3.535

O'Neill JP, Parker TA (1978) Responses of birds to a snowstorm in the Andes of southern Peru. The Wilson Bulletin 90:446-449

Pepin $\mathrm{N}$ et al. (2015) Elevation-dependent warming in mountain regions of the world. Nature Climate Change 5:424-430 doi:https://doi.org/10.1038/nclimate2563

R Development Core Team (2019) R: A language and environment for statistical computing. 3.6.2 edn. R Foundation for Statistical Computing, Vienna, Austria. http://www.r-project.org/ 
Resano-Mayor J et al. (2020) Partial migration of White-winged Snowfinches is correlated with winter weather conditions. Global Ecology and Conservation 24:e01346

doi:https://doi.org/10.1016/j.gecco.2020.e01346

Resano-Mayor J et al. (2017) Integrating genetic and stable isotope analyses to infer the population structure of the White-winged Snowfinch Montifringilla nivalis in Western Europe. Journal of Ornithology 158:395-405 doi:https://doi.org/10.1007/s10336-016-1413-8

Rumeu B, Padilla DP, Nogales M (2009) The key role of a ring ouzel Turdus torquatus wintering population in seed dispersal of the endangered endemic Juniperus cedrus in an insular environment. Acta Ornithologica 44:199-204 doi:https://doi.org/10.3161/000164509X482786

Ryall C, Briggs K (2006) Some factors affecting foraging and habitat of Ring Ouzels Turdus torquatus wintering in the Atlas Mountains of Morocco. ABC Bulletin 13:60-74

Schmaljohann H (2018) Proximate mechanisms affecting seasonal differences in migration speed of avian species. Scientific Reports 8:4106 doi:10.1038/s41598-018-22421-7

Sim IMW, Green M, Rebecca GW, Burgess MD (2015) Geolocators reveal new insights into Ring Ouzel Turdus torquatus migration routes and non-breeding areas. Bird Study 62:561-565 doi:https://doi.org/10.1080/00063657.2015.1077779

Stull R (2016) Practical meteorology: an algebra-based survey of atmospheric science. University of British Columbia, Vancouver

Sumner MD, Wotherspoon SJ, Hindell MA (2009) Bayesian estimation of animal movement from archival and satellite tags. PLoS One 4:e7324 doi:https://doi.org/10.1371/journal.pone.0007324

Tellería JL, Carrascal LM, Santos T (2014) Species abundance and migratory status affects large-scale fruit tracking in thrushes (Turdus spp.). Journal of Ornithology 155:157-164

doi:https://doi.org/10.1007/s10336-013-0997-5

Tellería JL, Hera IDL, Ramírez Á, Santos T (2011) Conservation opportunities in spanish juniper Juniperus thurifera woodlands: the case of migratory thrushes Turdus spp. Ardeola 58:57-70 doi:https://doi.org/10.13157/arla.58.1.2011.57

Tsai P-Y, Ko C-J, Chia SY, Lu Y-J, Tuanmu M-N (2021) New insights into the patterns and drivers of avian altitudinal migration from a growing crowdsourcing data source. Ecography 44:75-86 doi:https://doi.org/10.1111/ecog.05196

Webster MS, Marra PP, Haig SM, Bensch S, Holmes RT (2002) Links between worlds: unraveling migratory connectivity. Trends in Ecology \& Evolution 17:76-83 doi:https://doi.org/10.1016/S0169-5347(01)02380- 
Wingfield JC et al. (2004) Arctic spring: the arrival biology of migrant birds. Acta Zoologica Sinica 50:948960

Winkler DW et al. (2014) Cues, strategies, and outcomes: how migrating vertebrates track environmental change. Movement Ecology 2:10 doi:https://doi.org/10.1186/2051-3933-2-10

Wotherspoon S, Sumner M, Lisovski S (2016) TwGeos: Basic data processing for light-level geolocation archival tags. R package ver. 0.0-1.

Zamora R (1990) The fruit diet of Ring Ouzels (Turdus torquatus) wintering in the Sierra Nevada. Alauda 58:67-70

\section{Tables}

Table 1: Summary statistics and schedule of dispersal and migration from the five ring ouzel individuals equipped with multi-sensor loggers. The total distance indicates the great circle distance from the breeding site to the furthest winter location, and not the whole trajectory distance. Travel speed has been calculated as total distance divided by the duration of migration (i.e. rounded number of days from the first to the last migratory flight). 'Nights on migration' stand for the number of nights with ascertained migratory flight activity. 


\begin{tabular}{|c|c|c|c|c|c|}
\hline & $\overline{\mathrm{AdF}}$ & 2cyM & AdM-1 & AdM-2 & AdM-3 \\
\hline Age and sex & $\begin{array}{c}\text { adult } \\
\text { female }\end{array}$ & $\begin{array}{l}2^{\text {nd }} \text {-year } \\
\text { male }\end{array}$ & $\begin{array}{l}\text { adult } \\
\text { male }\end{array}$ & $\begin{array}{l}\text { adult } \\
\text { male }\end{array}$ & $\begin{array}{l}\text { adult } \\
\text { male }\end{array}$ \\
\hline Period & $\begin{array}{l}2017- \\
2018\end{array}$ & $2017-2018$ & $\begin{array}{l}2018- \\
2019\end{array}$ & $\begin{array}{l}2018- \\
2019\end{array}$ & $\begin{array}{l}2019- \\
2020\end{array}$ \\
\hline Total distance $(\mathrm{km})$ & 1158 & 2115 & 1868 & 2284 & 1739 \\
\hline $\begin{array}{l}\text { Post-breeding dispersal } \\
\text { start }\end{array}$ & 2-Jul & $5-\mathrm{Jul}$ & 17-Jun & 28-Jun & 19-Jun \\
\hline Duration (days) & 73 & 45 & 83 & 103 & 77 \\
\hline \multicolumn{6}{|l|}{ Autumn migration } \\
\hline Departure & 13-Sep & 20-Aug & 9-Sep & 9-Oct & 3-Sep \\
\hline Duration (days) & 54 & 83 & 46 & 27 & 55 \\
\hline Arrival & 6-Nov & 11-Nov & 24-Oct & $5-\mathrm{Nov}$ & 29-Oct \\
\hline Nights on migration & 11 & 31 & 8 & 7 & 13 \\
\hline Travel speed (km/day) & 21.1 & 25.5 & 40.6 & 84.6 & 31.6 \\
\hline Cumulative flight hours & 30.7 & 75.2 & 43.9 & 42.7 & 44.8 \\
\hline \multicolumn{6}{|l|}{ Spring migration } \\
\hline Departure & 27-Mar & 19-Mar & 11-Mar & 22-Mar & - \\
\hline Duration (days) & 9 & 18 & 20 & 9 & - \\
\hline Arrival & 5-Apr & 6-Apr & 31-Mar & 1-Apr & - \\
\hline Nights on migration & 5 & 7 & 7 & 5 & - \\
\hline Travel speed (km/day) & 128.7 & 117.5 & 93.4 & 253.8 & - \\
\hline Cumulative flight hours & 21.3 & 36.2 & 40.8 & 41.7 & - \\
\hline
\end{tabular}

\section{Figures}




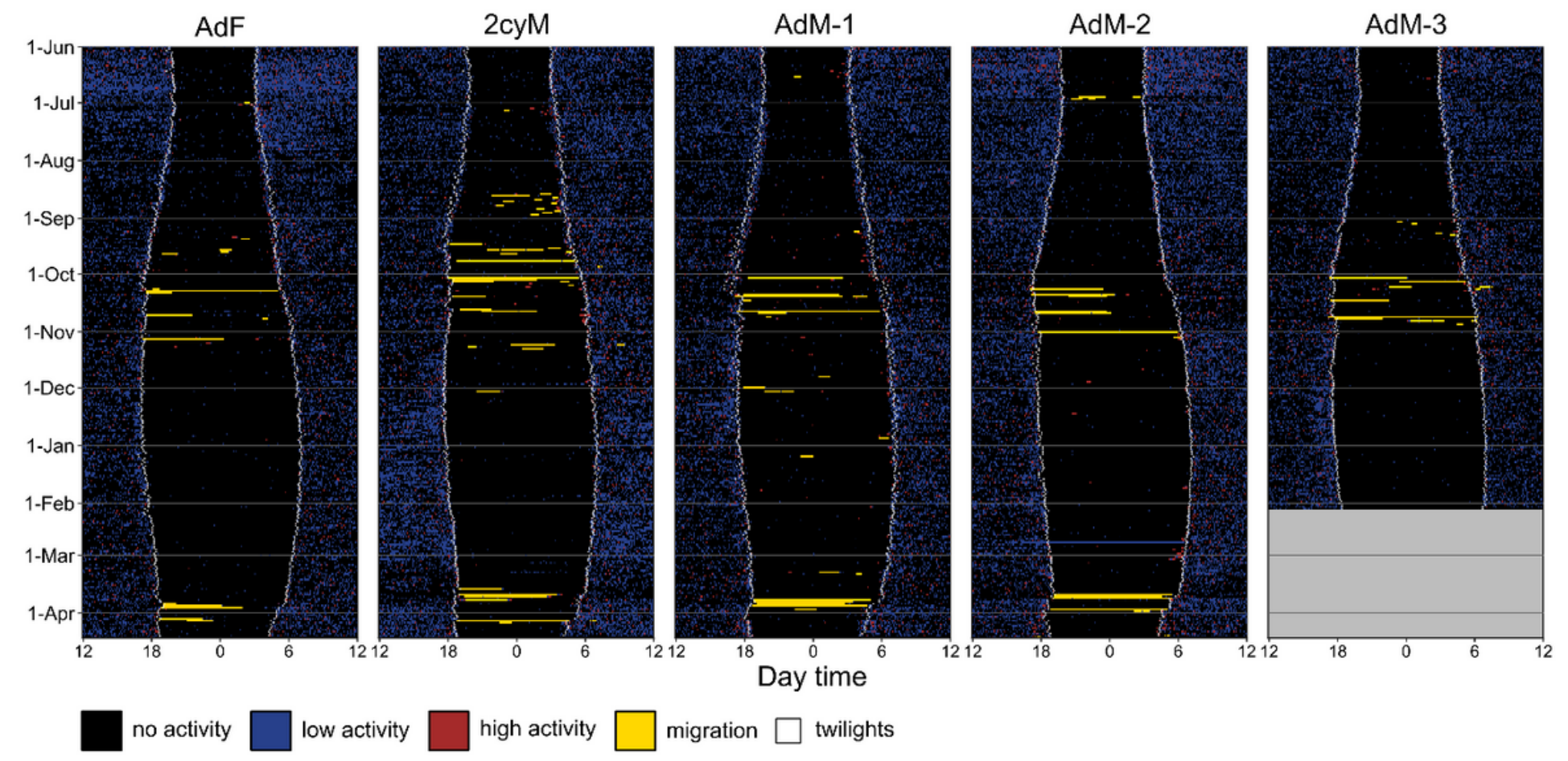

\section{Figure 1}

Actograms of five ring ouzels equipped with multi-sensor loggers, showing the annual activity pattern as classified into four categories of behaviour. Small white squares show the timing of the twilights as estimated from the individual light sensor of the tag. The cut between two successive 24-h periods is set at noon to enhance the visualization of a nocturnal migratory flight along a single line. 


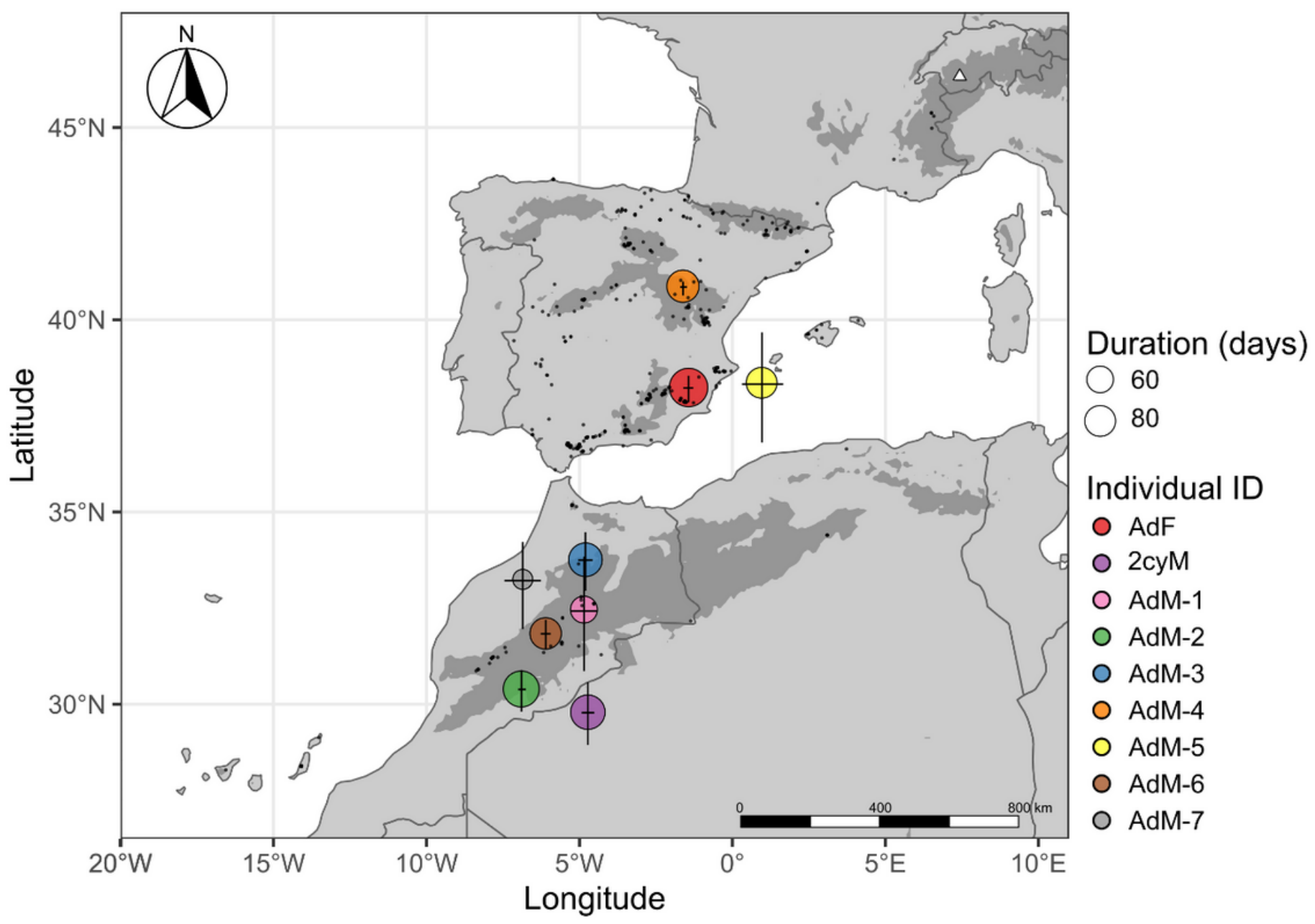

Figure 2

Longest stationary winter locations of nine ring ouzel individuals as retrieved from geolocator data. Error bars around locations represent $95 \%$ credible intervals while the size of circle is proportional to stay duration. Winter sightings of ring ouzels (December to February) are shown as small black dots and were accessed via GBIF (https://doi.org/10.15468/dl.p6ez7a). Areas shaded in dark grey are above the contour line of $1000 \mathrm{~m}$ asl. 


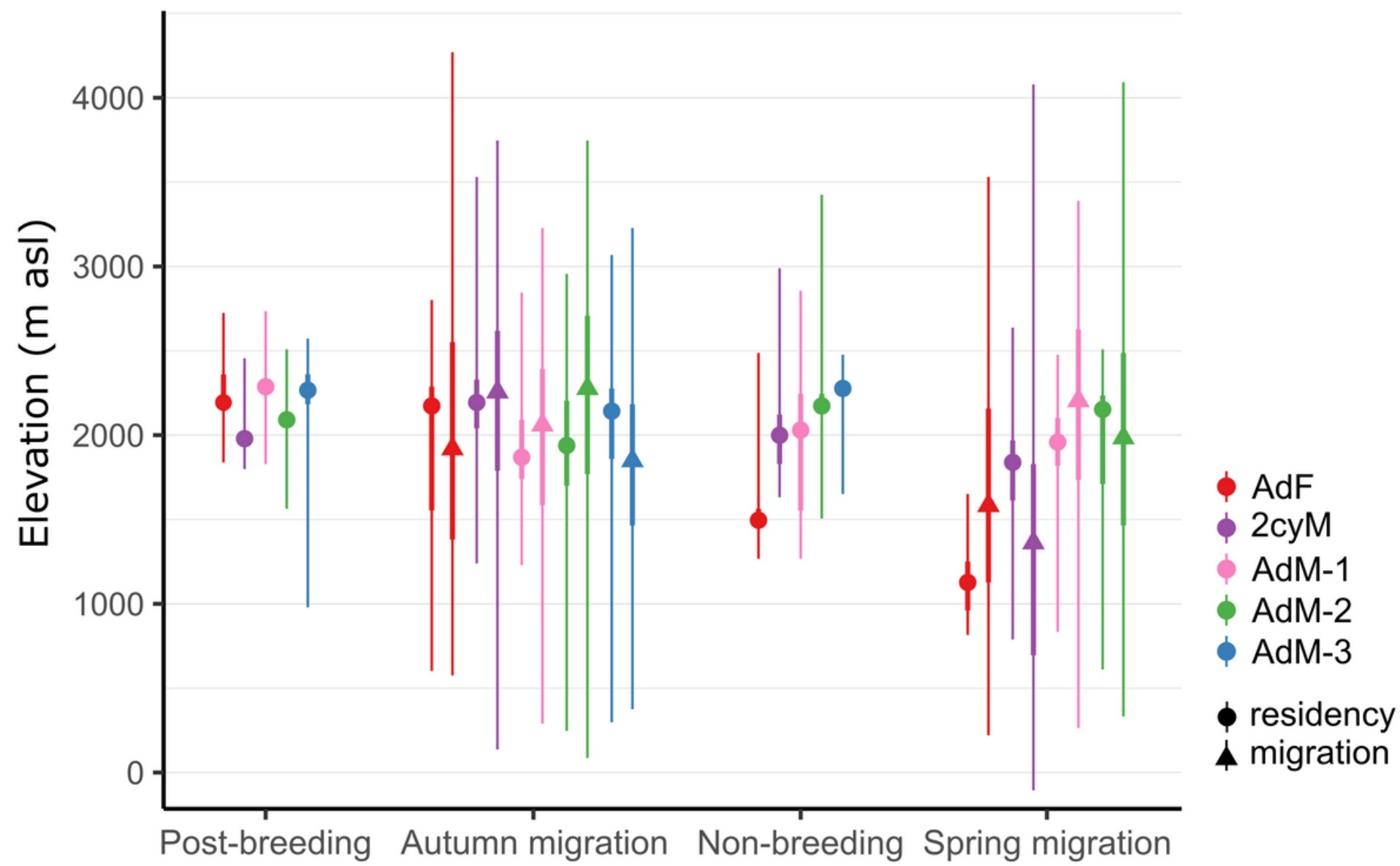

Figure 3

Median elevation estimates, at four stages of the annual cycle, for five ring ouzels equipped with multisensor loggers. For autumn and spring migration, readings during stopovers (circles) are separated from those during active, mostly nocturnal migration (triangles). Bold bars represent the lower to upper quartile range and thin bars the total range of readings ( $\min$ to max). 
2018

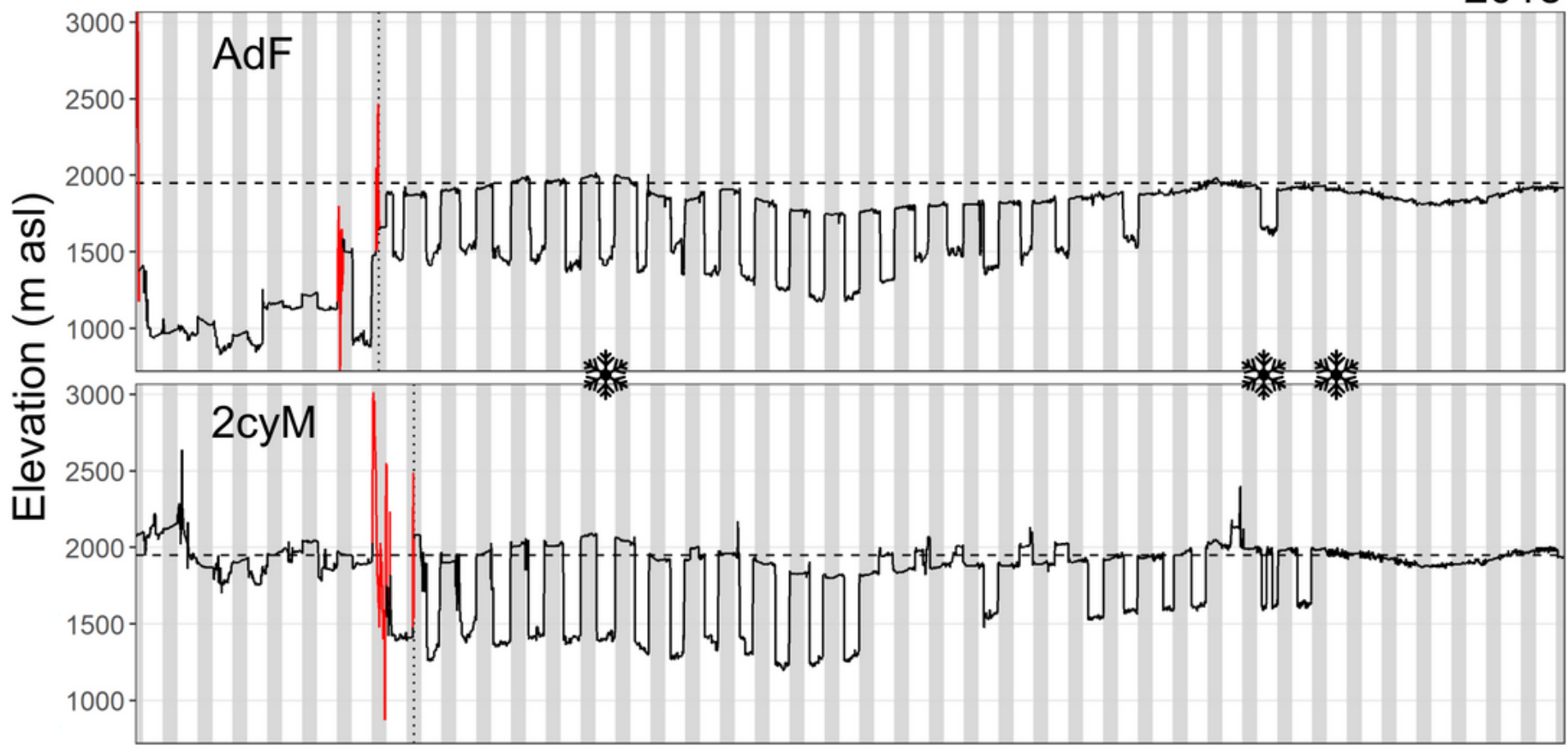

2019

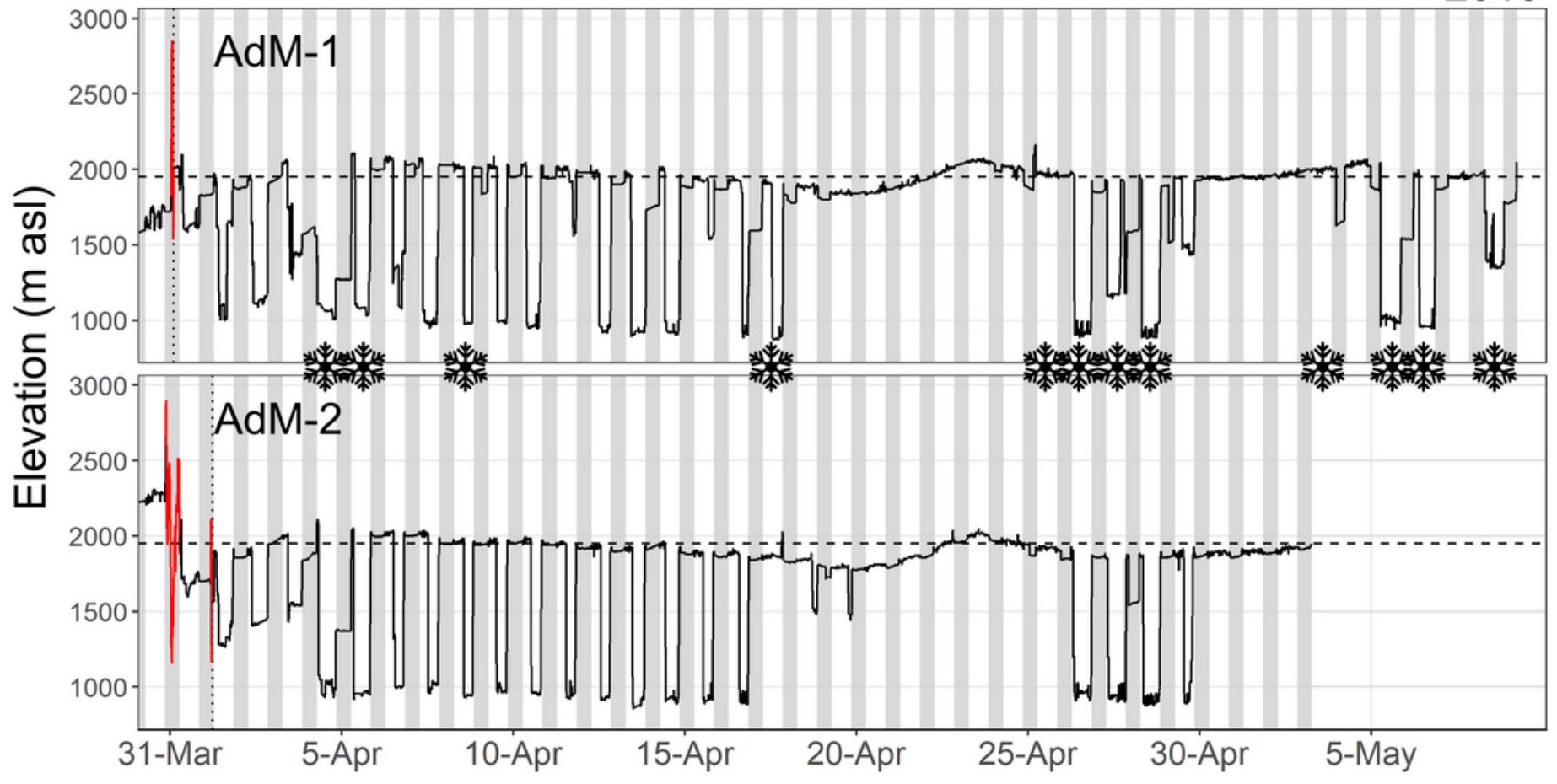

Figure 4

Continuous elevation estimates (5-min intervals) from four ring ouzels upon arrival (date: vertical dotted line) on the breeding grounds in spring. Grey zones symbolize nighttime and the horizontal dashed lines indicate the mean elevation of the study area. Elevation estimates displayed in red refer to migratory flights. Snowflake icons indicate a new snowfall ( $\geq 1 \mathrm{~cm}$ fresh snow) as measured at a nearby weather station (4.1 km distance, $2390 \mathrm{~m}$ asl). 


\section{Supplementary Files}

This is a list of supplementary files associated with this preprint. Click to download.

- 240421BarrasetalSupplnfoJAvBio.docx 